\title{
Factors contributing towards research productivity in higher education
}

\author{
Caroline Henry ${ }^{1}$, Nor Azura Md Ghani², Umi Marshida Abd Hamid ${ }^{3}$, Ahmad Naqiyuddin Bakar \\ ${ }^{1,2}$ Centre of Statistical and Decision Science Studies, Faculty of Computer and Mathematical Sciences, \\ Universiti Teknologi MARA, Malaysia \\ ${ }^{2}$ National Design Centre, Universiti Teknologi MARA, Malaysia \\ ${ }^{3}$ Faculty of Applied Sciences, Universiti Teknologi MARA, Malaysia \\ ${ }^{4}$ Faculty of Administrative Science and Policy Studies, Universiti Teknologi MARA, Malaysia \\ ${ }^{1}$ Kolej Vokasional Labuan, Malaysia
}

\section{Article Info}

Article history:

Received Dec 3, 2019

Revised Feb 8, 2020

Accepted Feb 25, 2020

\section{Keywords:}

Higher education

Logistic regression

Research output

Research productivity

\begin{abstract}
Research Productivity (RP) is the key element in the establishment of ranking and rating system in the Higher Education (HE) sector. Despite of the many initiatives taken to enliven the research culture among academic staff, there are still constraints and resistance towards conducting research. Therefore, this study attempts to identify the factors affecting RP and develop an appropriate model to determine the RP of an academic staff in Universiti Teknologi MARA (UiTM). In this study, 5 research related indicators were used in the determination of RP. Since the population size of UiTM is large, the primary data was collected by using questionnaire survey and stratified random sampling. The variables that were found to be significant in determining RP of an academic staff were age cohort, highest qualification, cluster and track emphasis. Satisfaction towards annual KPI, UiTM current policy and monthly income were also found to influence the RP of an academic staff. In addition, perceiving the role of principal investigator as a chore and burden and supervising and graduating a $\mathrm{PhD}$ student perception as burden and pleasure were also found to be affecting RP. Using these variables, Logistic Regression Model was used to determine the RP of an academic staff in UiTM. In conclusion, personal, environmental and behavioural factors were found to have influence on the RP among academic staff of UiTM. Therefore, generally it is possible to maximize the RP of academic staff by identifying the factors influencing RP followed by strategic management and proper monitoring system.
\end{abstract}

This is an open access article under the CC BY-SA license.

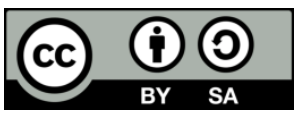

\section{Corresponding Author:}

Nor Azura Md Ghani,

Centre of Statistical and Decision Science Studies,

Faculty of Computer and Mathematical Sciences,

Universiti Teknologi MARA,

40450 Shah Alam, Selangor, Malaysia.

Email: azura@tmsk.uitm.edu.my

\section{INTRODUCTION}

Despite of the criticisms on the numerous variation in university ranking system, these systems still plays a major role in the HE sector. The most compelling evidence is that these ranking systems had a transformative impact and influence on HE sector and its stakeholders around the world like students and parents, governments and policymakers, employers and industry, peer institutions and research partners, 
philanthropists and alumni to access a specific university' ranking and rating in various purposes [1]. Two (2) of the most known ranking system are namely Academic Ranking of World Universities (ARWU) and World University Rankings (WUR), being the obsession of 17,000 Higher Education Institutions (HEIs) worldwide to be ranked in the top 100 as stated by [2]. On the institutional perspective however, these ranking platforms had indirectly created a healthy competition among all the HEIs in Malaysia in competing to fulfil the criteria of being recognized as Research University (RU). In addition, the Malaysian government had also allocated a large amount of fund to support the RU to continuously produce innovations and quality research outputs [3]. These systems had encouraged HEIs to set strategic goals, strengthen their research capability and intensify their productivity [4]. Research element is the most common shared criteria used among ranking and rating instruments. In United Kingdom (UK), according to Research Excellence Framework (REF) [5], HE funding bodies developed the REF for research assessment that is to secure the continuation of a world-class, dynamic and responsive research base across the full academic spectrum within UK HE. Similarly, in Malaysia, the Ministry of Higher Education (MOHE) implemented Malaysia Research Assessment (MyRA), an instrument to assess research, development and innovation activities in all universities. In align, the use of Key Performance Indicator (KPI) in HE ensure that academic staff are producing output to enhance their visibility as well as for the institution. The most common KPI set by HEIs are the number of scholarly publication produced annually. To clarify that, there has been numerous studies in measuring RP with the use of scholarly publication being the top indicator [6-9]. Other research related indicators should also be included in measuring RP to encourage academic staff to conduct research. Personal factor are commonly used in measuring RP whereby variables such as age, experience and level of qualification has been reported to have strong correlation with RP [6, 8-10]. Environmental factor including research culture, workload, research assistance and research funding are also important to be considered in RP. Workload affects RP as it controls the ability for the academic to do research [9, 10]. Research funding is one of the essential components to aid researchers in doing research as well as producing outputs [6, 9, 11, 12]. Management factor are related to the policies and KPI that is usually set by the institution as it is the goal that the institution strives to achieve. The use of performance indicators for HEI is needed to improve accountability of HEI [13]. Lastly, behavioural factor include variables like motivation, incentive, promotion and recognition. The lack of these variables had demotivated young researchers to do research, which indicates that behavioural factors also affect RP. In fact, human behavioral aspects were also found to be a factor in a study conducted by Mokhtar and Noordin [14]. Numerous studies have shown that motivation to do research has a significant correlation with RP [15-21]. Based on a study conducted in Binus University, Indonesia, the emphasis on research publications in KPI from the higher management motivates academic staff to do research as well as increasing RP [8]. On the other hand, logistic regression is widely used in various fields and sectors, including predicting staff performance in an organization. In a study conducted by Francis [22], marital status was found to be a significant factor in distinguishing staff performance as identified from the outlined factors influencing the staffs' performance in a selected small public sector. Yaacob et al. [23] also used logistic regression as one of the techniques to determine as well as to predict UiTM undergraduate student's performance which is said to be beneficial for innovation in modern educational systems. Being said that logistic regression model is used in various fields and sectors, Samsudin et al. [24] had proposed an enhancement features to detect YouTube spam which includes logistic regression as one of the tools of comparision. Based on a study conducted in UiTM by Henry et al. [11] which investigated the relationship between research funding and the citation impact of UiTM's research publications, it was found that financial support from funding bodies in terms of research grants is acknowledged as a factor which can influence overall impact and number of times a publication is cited. Moreover, scholarly publication is often being used to measure the productivity of an institution and has been recognized worldwide as a medium through which to expand the social and the knowledge economy. Up until today, there is no standard measurement to determine RP of an institution. Dhillon et al [6] conducted a study which identifies the factors associated with scholarly publication. However, this paper emphasis not only the number of publications but also other indicators such as the amount of research grant acquired, the status of the principal investigator, number of $\mathrm{PhD}$ students graduated, and the number of intellectual properties registered were also taken account in measuring RP. These criteria are based on the criteria in MyRA' Instrument that yields a large proportion of marks and also align with the world ranking and rating systems such as QS Ranking and THE. This paper presents the effect of personal, environmental, management and behavioural factors on the RP of an academic staff by the use of logistic regression model to determine the RP of an academic staff. 


\section{RESEARCH METHOD}

\subsection{Framework}

Only academic staff of UiTM which are located in Selangor campuses were selected for this study in align with the university ranking and rating system practices. A previous study was conducted in Universiti Teknologi Malaysia (UTM) that studied the association of personal, environmental and behavioural factors with scholarly publication [6]. However, in this case of UiTM, an additional factor was added to the framework that is management factor as shown in Figure 1. Management factors consists of publication KPI, KPI weightage, rewards or incentives, and reviewing process. The need of this factor is necessary as KPI based outcomes is now being used to measure annual performance of an academic staff.

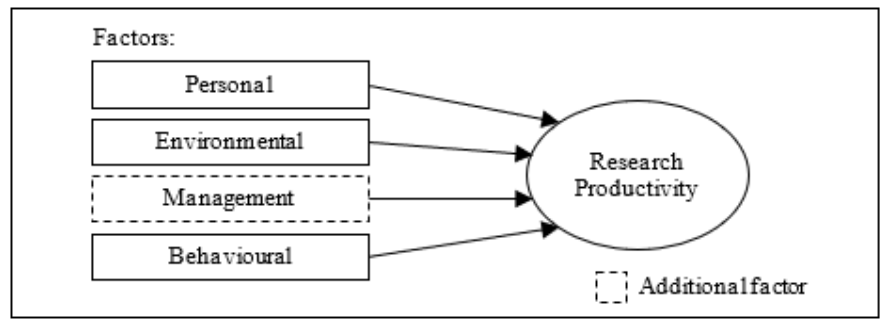

Figure 1. Theoretical framework as adapted from Dhillon et al [6]

\subsection{Determination of Research Productivity}

Figure 2 shows the flowchart to determine the RP of each academic staff. Five (5) criteria were used to determine the status of an academic staff which were the amount of research grant acquired, status of principal investigator, number of publication, number of $\mathrm{PhD}$ graduates and number of intellectual property. Each criteria required either a yes or no, hence as long as an academic fulfils any 1 out of the 5 criteria, the academic is considered to be productive.

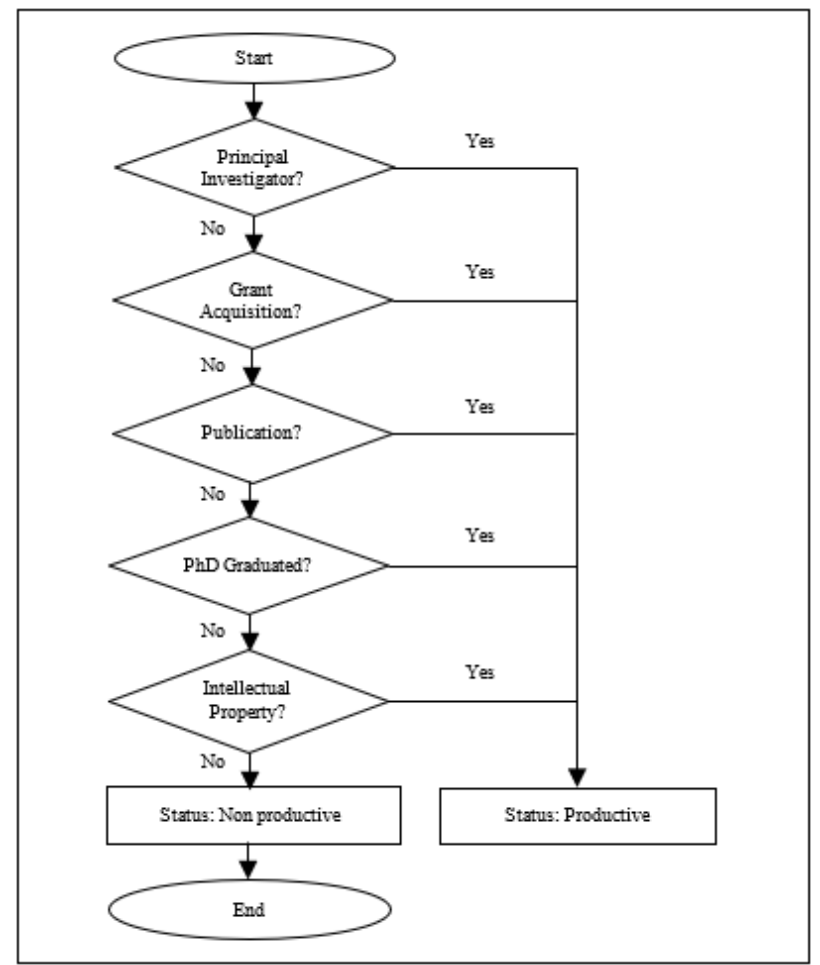

Figure 2. Research productivity determination flowchart 


\subsection{Logistic regression}

Logistic regression is widely used in various fields and sectors, commonly for dichotomous dependent variables. In the HE sector, there have been several studies on applying logistic regression to address student enrolment and retention. This approach was found to be imperative in maintaining and improving the enrolment rate in the future [25]. The objective of the model proposed herein is to determine the conditional probability of a specific academic staff belonging to a status (productive or non productive), given the values of the independent variables of that academic staff. For this study, the logistic regression was used to model the event $\mathrm{Y}=1$ (productive).

$$
\begin{aligned}
& \log \left(\frac{P(Y=1)}{1-P(Y=1)}\right)=\alpha+\beta_{1} X_{1}+\beta_{2} X_{2}+\beta_{3} X_{3}+\beta_{4} X_{4} \\
& P(Y=1)=\frac{1}{\left(1+e^{-z}\right)}
\end{aligned}
$$

Where:

$\begin{array}{ll}P(Y=1) & =\text { the probability of being productive } \\ \mathrm{z} & =\alpha+\beta_{1} X_{1}+\beta_{2} X_{2}+\beta_{3} X_{3}+\beta_{4} X_{4} \\ \alpha & =\text { Constant } \\ \beta_{1} & =\text { Personal Factor } \\ \beta_{2} & =\text { Environmental Factor } \\ \beta_{3} & =\text { Management Factor } \\ \beta_{4} & =\text { Behavioural Factor }\end{array}$

\subsection{Data collection}

\subsubsection{Sampling design}

Based on a similar studies conducted in identifying factors associated with RP, Sulo, Kendagor, Kosgei, Tuitoek and Chelangat [9] used a combination of stratified and simple random sampling while Wichian, Wongwanich and Bowarnkitiwong [10] used only simple random sampling. These studies were found to obtain the most reasonable number of respondents suitable with the size of UiTM. Hence, stratified random sampling were used in this study to calculate the number of respondents. UiTM consists of 27 faculties, $F_{n}$, in which divided into 2 status that is productive and non productive as in Figure 3.

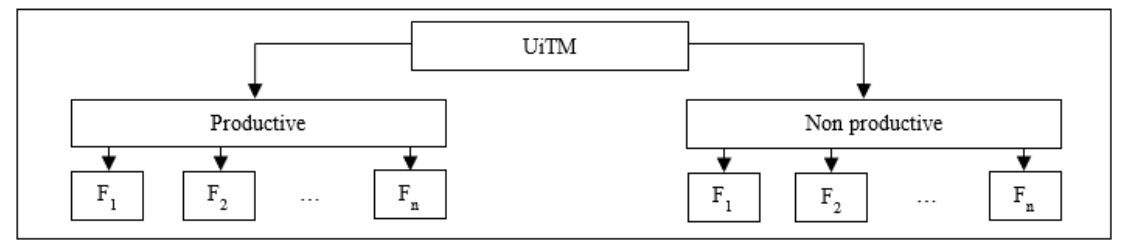

Figure 3. Population of UiTM by RP status

This study focused on these 2 status of which contain the 27 faculties. Hence, stratified random sampling was utilised to determine the approximate number of sample size required as in (3) [26].

$$
n=\frac{\frac{N_{1}^{2} \sigma_{1}^{2}}{W_{1}}+\frac{N_{2}^{2} \sigma_{2}^{2}}{W_{2}}}{N^{2} D+N_{1} \sigma_{1}^{2}+N_{2} \sigma_{2}^{2}} \text { where, } D=\left(\frac{d}{\frac{d}{2}}\right)^{2}
$$

Where:

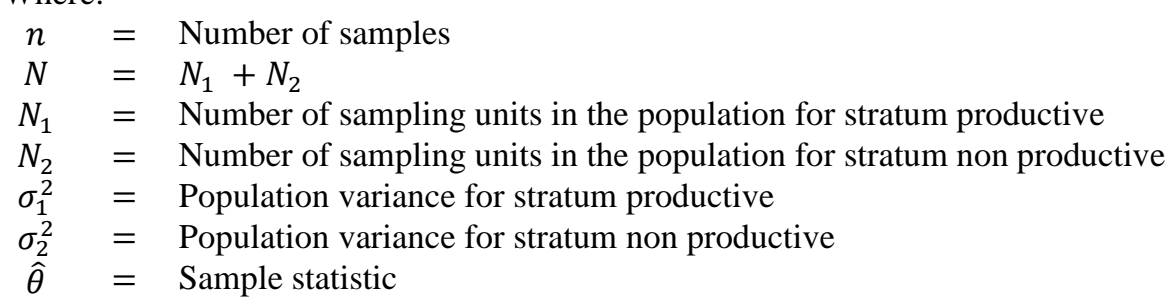




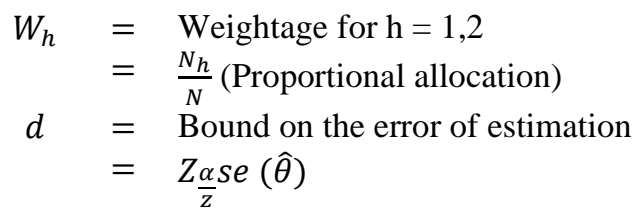

Table 1 shows the number of academic staff by status and the number of respondents gathered from the pilot study. Based on the pilot study, mean and standard deviation for each factor was retrieved as presented in Table 2.

Table 1. Weightage of academic staff

\begin{tabular}{cccc}
\hline Status & No. of Academic Staff, $N_{i}$ & Number of Respondents, $n_{i}$ & Weightage, $W_{h}$ \\
\hline$(1)$ & 2,015 & 32 & 0.5351 \\
$(2)$ & 1,751 & 10 & 0.4649 \\
\hline Note: & & & \\
(1) $=$ Productive & & &
\end{tabular}

Table 2. Mean and standard deviation by factor and status

\begin{tabular}{lccc}
\hline Factor & Status & Mean & Standard Deviation, $\sigma_{2}^{2}$ \\
\hline Environmental & $(1)$ & 3.4903 & 0.9049 \\
& $(2)$ & 3.6644 & 0.5386 \\
Management & $(1)$ & 3.1692 & 0.7383 \\
& $(2)$ & 2.9000 & 0.6976 \\
Behavioural & $(1)$ & 3.6099 & 0.7551 \\
& $(2)$ & 3.3444 & 0.8527 \\
\hline
\end{tabular}

The number of sample size is then calculated based on factor and the highest number is selected for this study as summarized in Table 3. However, the research nature in UiTM varies according to faculty as Science and Technology (S\&T) based faculties are more likely to do research compared to Social Sciences (SS) based faculties. Hence, 456 respondents were selected from S\&T based faculties while another 456 respondents were selected from SS based faculties. In this study, track emphasis of the academic staff was also taken into account as the number of respondents were selected proportionally from the population as summarized in Table 4.

Table 3. Summary of sample size determination by factor

\begin{tabular}{cccc}
\hline Status & Environmental & Management & Behavioural \\
\hline$(1)$ & 211 & 244 & 234 \\
$(2)$ & 184 & 212 & 204 \\
Total & 395 & 456 & 438 \\
\hline
\end{tabular}

Table 4. Sample size for S\&T and SS based faculties

\begin{tabular}{|c|c|c|c|c|c|}
\hline \multirow[b]{2}{*}{ Status } & \multirow[b]{2}{*}{ Track } & \multicolumn{2}{|c|}{ S\&T } & \multicolumn{2}{|c|}{ SS } \\
\hline & & $\begin{array}{c}\text { No. of } \\
\text { Academic Staff }\end{array}$ & $\begin{array}{c}\text { No. of } \\
\text { Respondent }\end{array}$ & $\begin{array}{c}\text { No. of } \\
\text { Academic Staff }\end{array}$ & No. of Respondent \\
\hline \multirow{2}{*}{ (1) } & TL & 893 & 161 & 458 & 169 \\
\hline & $\overline{\mathrm{TL}}$ & 460 & 83 & 204 & 75 \\
\hline \multirow{2}{*}{ (2) } & TL & 636 & 185 & 871 & 181 \\
\hline & $\overline{\mathrm{TL}}$ & 93 & 27 & 151 & 31 \\
\hline \multicolumn{2}{|c|}{ Total } & 2.082 & 456 & 1.684 & 456 \\
\hline
\end{tabular}

\subsubsection{Primary data and sources}

Primary data was collected by conducting a survey using an adapted questionnaire. Meanwhile, secondary data was collected from UiTM's Institute of Research Management and Innovation (IRMI) such as the amount of research grant acquired, the status of the principal investigator, the number of publications, number of PhD students graduated, and number of intellectual property registered for the year of 2016. 


\section{RESULTS AND DISCUSSION}

Omnibus Test was used to evaluate the significance of the logistic regression model. Based on the result in Table 5, the p-value is less than 0.05 indicating that the model is significant. Hosmer and Lemeshow test was used to assess the relationship between observed and predicted probabilities match as previously demonstrated by Salkind [27]. It was found that the model is not significant (Table 6), indicating that logistic regression model fits the data. The Nagelkerke R Square shows that $46 \%$ of the variation in the outcome variable (Productive) is explained by this logistic model as in Table 7. From the classification percentage in Table 8 , the percentage of correct classification is $78.2 \%$ which is considered to be good as many studies havefound that the classification percentage above $70 \%$ is acceptable [28].

Table 5. Omnibus test

\begin{tabular}{llll}
\hline & Chi-square & df & p-value \\
\hline & 266.867 & 85 & $0.000^{*}$ \\
\hline Note: & $*$ Significance level based on 0.05 & &
\end{tabular}

Table 6. Hosmer and Lemeshow test

\begin{tabular}{ccc}
\hline Chi-square & df & p-value \\
\hline 5.000 & 8 & 0.758 \\
\hline
\end{tabular}

Table 7. Variation explained by the model

\begin{tabular}{ccc}
\hline-2 Log likelihood & Cox \& Snell R Square & Nagelkerke R Square \\
\hline 595.442 & 0.338 & 0.459 \\
\hline
\end{tabular}

Table 8. Classification results for logistic regression model

\begin{tabular}{|c|c|c|c|c|}
\hline & \multirow{3}{*}{ Observed } & \multicolumn{3}{|c|}{ Predicted } \\
\hline & & & & Percentage Correct \\
\hline & & Non productive & Productive & Percentage Correct \\
\hline \multirow{3}{*}{$\mathrm{RP}$} & Non productive & $\begin{array}{c}169 \\
(67.9 \%)\end{array}$ & $\begin{array}{c}80 \\
(32.1 \%)\end{array}$ & 67.9 \\
\hline & \multirow[t]{2}{*}{ Productive } & $\begin{array}{c}61 \\
(15.3 \%)\end{array}$ & $\begin{array}{c}337 \\
(84.7 \%)\end{array}$ & 84.7 \\
\hline & & 11 percentage & & 78.2 \\
\hline
\end{tabular}

The odds ratios can be further explained using the value of $\operatorname{Exp}(\mathrm{B})$ in Table 9. In this study, academic staff who have a doctoral degree were 7 times more likely to be productive compared to those with professional qualification. In addition, academic staff who perceive supervision and producing a $\mathrm{PhD}$ graduate as a burden were 11 times more likely to be productive compared to those who perceive otherwise. It is found that this category of productive researchers produce scholarly outputs as a joint output with their postgraduate students at the same time fulfilling the requirements of the doctoral degree. This is in agreement with the high ratios of graduate students to academic staffs correlate with RP [7, 29]. Either way, both the academic staff and student would benefit from this and increases the institution's RP. This model can also be used to predict the RP of an academic staff by using the contributing factors (significant covariate) that influences the RP of academic staff. In a situation of an academic staff aged below 40 years old, owns a doctoral degree, belong to a S\&T based faculty, choses TL, and is satisfied with his annual KPI, UiTM's policy, monthly income and agrees that leading a research project, publishing and supervising and graduating a $\mathrm{PhD}$ student is a chore and pleasure and strongly disagree that leading a research project, publishing and supervising and graduating a $\mathrm{PhD}$ student is a burden, the $\mathrm{z}$ value is as presented in (4).

$$
\mathrm{Z}=0.447+1.181+2.012+0.77-0.822-1.114=2.474
$$

Thus, the probability of being productive for this academic staff is formulated by (4).

$$
\mathrm{P}(\text { productive })=\frac{1}{1+\mathrm{e}^{-2.474}}=0.922
$$

The probability of this academic staff being classified as productive is 0.922 indicating that the likelihood of being productive is high. Based on this finding, higher management can groom this 
academic staff into becoming a well-known researcher in the future by giving support in term of internal grants, incentives and so on.

Table 9. Parameter estimates and test statistics

\begin{tabular}{|c|c|c|c|c|c|c|c|}
\hline Factor & Variable & $\mathrm{B}$ & S.E. & Wald & df & $p$-value & $\operatorname{Exp}(B)$ \\
\hline \multirow[t]{8}{*}{ Personal } & Age Cohort & & & & & & \\
\hline & Less than 40 years old & 1.181 & 0.569 & 4.301 & 1 & $0.038 *$ & 3.257 \\
\hline & Highest Qualification & & & & & & \\
\hline & $\mathrm{PhD}$ & 2.012 & 0.517 & 15.129 & 1 & $0.000 *$ & 7.477 \\
\hline & Cluster & & & & & & \\
\hline & $\mathrm{S} \& \mathrm{~T}$ & 0.770 & 0.240 & 10.261 & 1 & $0.001 *$ & 2.159 \\
\hline & Lecturer Track Assignment Emphasis & & & & & & \\
\hline & Teaching and Learning & -0.822 & 0.314 & 6.856 & 1 & $0.009 *$ & 0.439 \\
\hline \multirow{8}{*}{ Environmental } & Are you satisfied with the annual KPIs to be achieved? & & & & & & \\
\hline & Absolutely not satisfied & -2.678 & 1.342 & 3.981 & 1 & $0.046 *$ & 0.069 \\
\hline & Not satisfied & -1.883 & 0.848 & 4.933 & 1 & $0.026 *$ & 0.152 \\
\hline & Neutral & -2.615 & 0.769 & 11.579 & 1 & $0.001 *$ & 0.073 \\
\hline & $\begin{array}{l}\text { Are you satisfied with UiTM's current policy on job } \\
\text { scope? }\end{array}$ & & & & & & \\
\hline & Not satisfied & 2.129 & 0.969 & 4.821 & 1 & $0.028 *$ & 8.402 \\
\hline & Are you satisfied with your monthly income? & & & & & & \\
\hline & Absolutely not satisfied & -3.041 & 1.048 & 8.419 & 1 & $0.004 *$ & 0.048 \\
\hline \multirow[t]{12}{*}{ Behavioural } & Do you feel that leading a research project is a chore? & & & & & & \\
\hline & Strongly Disagree & -2.827 & 1.305 & 4.696 & 1 & $0.030 *$ & 0.059 \\
\hline & Do you feel that leading a research project is a burden? & & & & & & \\
\hline & Agree & -2.189 & 0.770 & 8.083 & 1 & $0.004 *$ & 0.112 \\
\hline & Neutral & -2.318 & 0.718 & 10.428 & 1 & $0.001 *$ & 0.098 \\
\hline & Disagree & -1.485 & 0.657 & 5.109 & 1 & $0.024 *$ & 0.226 \\
\hline & $\begin{array}{l}\text { Do you find that supervising and graduating a } \mathrm{PhD} \\
\text { student is a burden? }\end{array}$ & & & & & & \\
\hline & Agree & 2.417 & 0.710 & 11.609 & 1 & $0.001 *$ & 11.217 \\
\hline & Neutral & 2.088 & 0.669 & 9.727 & 1 & $0.002 *$ & 8.068 \\
\hline & Disagree & 1.859 & 0.615 & 9.133 & 1 & $0.003 *$ & 6.420 \\
\hline & $\begin{array}{l}\text { Do you find that supervising and graduating a } \mathrm{PhD} \\
\text { student is a pleasure? }\end{array}$ & & & & & & \\
\hline & Agree & -1.114 & 0.510 & 4.779 & 1 & $0.029 *$ & 0.328 \\
\hline Constant & & 0.447 & 1.515 & 0.087 & 1 & 0.768 & 1.564 \\
\hline
\end{tabular}

Based on this study, age is one of the variables that were found to be affecting RP of an academic staff which validate the study conducted by Dhillon, Ibrahim and Selamat [6] and Wichian, Wongwanich and Bowarnkitiwong [10]. Academic staff who age cohort is less than 40 years old are considered to be young researcher who is the research leader in the future. Hence, these young researchers need to be groomed by giving awards and recognitions to motivate them to do more research and eventually increasing their own university's RP. In addition, possession a doctoral degree also influence the RP of an academic staff which support the findings for studies conducted by Nurhudatiana and Anggraeni [8] and Sulo, Kendagor, Kosgei, Tuitoek and Chelangat [9]. Other personal factor that were found to be affecting RP are cluster and track emphasis. As for the environmental factor, it was found that academic staff who are absolutely satisfied with their annual KPI and monthly income are more likely to be productive. However, it is found to be the reverse with UiTM's current policy on their job scope satisfaction as academic staff who are not satisfied are more likely to be productive. This shows that academic staff still perform in research regardless of the policy set by the higher management. In this study, an additional factor was added that is management factor. Unfortunately, all the variables are not significant indicating that management factor do not influence the RP of an academic staff. In the context of perception towards leading a research project, academic staff who positively perceive that leading a research project are more likely to be productive. In contrast, academic staff who less positively perceive that the act of supervising and graduating a $\mathrm{PhD}$ student are more likely to be productive. In achieving the KPI set by the higher management, academic staff especially has to face with the heavy workload which is disproportionate with their effort spent and benefit received in fulfilling every components of the required research related achievement [30]. As a matter of fact, workload directly affects $\mathrm{RP}$ as it controls the ability for the academic staff to do research [9, 10]. Correspondingly, this also demotivates academic staff to conduct research as to steer the university towards achieving its research agenda. Academic staff should feel that research is embedded in their job scope as it opens up to new opportunities in any form. In fact, the university should conduct a focus group study to find a solution in order to make research as a part of their daily routine as an academic staff. 


\section{CONCLUSION}

This paper presents the influence of personal, environmental, management and behavioural factors on RP among academic staff in UiTM by using logistic regression model to determine the RP of an academic staff. Up to date, there is no standard measurement to determine RP of an institution. However, scholarly publication is commonly used in measuring productivity of an institution and is recognized worldwide as a medium through which to expand the social and the knowledge economy. Given that, this paper emphasis not only the number of publications but also other indicators such as the amount of research grant acquired, the status of the principal investigator, number of $\mathrm{PhD}$ students graduated, and the number of intellectual properties registered were also taken account in measuring RP. These criteria are based on the criteria in MyRA' Instrument that yields a large proportion of marks and also align with the world ranking and rating systems such as QS Ranking and THE. From this study, RP of academic staff is influenced by personal, environmental and behavioural factors. This study managed to provide an insight of factors that affect RP among academic staff in UiTM. Proper management and monitoring of the performance of academic staff should be implemented in every HEIs so that the culture of research continues to expand. Being that, a Logistic Regression model to calculate individual RP has been built to facilitate the higher management in identifying the probability of an academic staff being productive. Research output can be done in many aspects not just in scholarly publication. In fact, these outputs are related to one another. The role of research is related to the job scope of an academic staff regardless of their preference in teaching or administration. Hence, academic staff should feel that research is a part of their career pathway.

\section{ACKNOWLEDGEMENTS}

Authors thank Universiti Teknologi MARA (UiTM) for supporting this study under the 600IRMI/MyRA 5/3/LESTARI (K) (004/2017) and the Institute of Research Management and Innovation (IRMI), UiTM for access to research related data.

\section{REFERENCES}

[1] E. Hazelkorn, "Rankings and the global reputation race," New directions for higher education, vol. 2014, no. 168, pp. 13-26, Dec. 2014

[2] E. Hazelkorn, "Learning to live with league tables and ranking: The experience of institutional leaders," Higher Education Policy, vol. 21, no. 2, pp. 193-215, Jun 2008.

[3] F. H. Amran, I. K. A. Rahman, K. Salleh, S. N. S. Ahmad and N. H. Haron, "Funding trends of research universities in Malaysia," Procedia-Social and Behavioral Sciences, vol. 164, pp. 126-134, Dec. 2014.

[4] J. S. Barrot, "Research impact and productivity of Southeast Asian countries in language and linguistics," Scientometrics, vol. 110, no. 1, pp. 1-15. Jan. 2017.

[5] A. E. RAE, "Research excellence framework," Policy, 38, 2009.

[6] S. K. Dhillon, R. Ibrahim, and A. Selamat, "Factors associated with scholarly publication productivity among academic staff: case of a Malaysian public university," Technology in Society, vol. 42, pp. 160-166, Aug. 2015.

[7] J. W. Kotrlik, J. E. Bartlett, C. C. Higgins and H. A. Williams, "Factors associated with research productivity of agricultural education faculty," Journal of Agricultural Education, vol. 43, no. 3, pp. 1-10, Dec. 2002.

[8] A. Nurhudatiana and A. Anggraeni, "Decision tree modeling for predicting research productivity of university faculty members," 2015 International Conference on Data and Software Engineering (ICoDSE), Nov. 25-26, 2015, Yogyakarta, Institute of Electrical and Electronics Engineers Inc., 2016.

[9] T. Sulo, R. Kendagor, D. Kosgei, D. Tuitoek and S. Chelangat, "Factors affecting research productivity in public universities of Kenya: the case of Moi University, Eldoret," Journal of Emerging Trends in Economics and Management Sciences, vol. 3, no. 5, pp. 475-484, Oct. 2012.

[10] S. N. Wichian, S. Wongwanich and S. Bowarnkitiwong, "Factors affecting research productivity of faculty members in government universities: Lisrel and Neural network analyses," Kasetsart Journal, vol. 12, no. 39, pp. 67-78, Jan. 2009.

[11] C. Henry, N. A. M. Ghani, H. Haron, U. M. A. Hamid, A. N. Bakar and A. T. A. Rahman, "The nexus between funding and research output: A case study in Universiti Teknologi MARA," International Journal of Engineering and Technology, vol. 7, no. 3.15, pp. 187-191, Aug. 2018.

[12] N. Jabnoun, "Economic and cultural factors affecting university excellence," Quality Assurance in Education, vol. 17, no. 4, pp. 416-429, Sep. 2009.

[13] D. R. Lewis, T. Ikeda and H. Dundar, "On the use of performance indicators in Japan's higher education reform agenda," Nagoya Journal of Higher Education, vol. 1, no. 2, pp. 67-98, 2001.

[14] M. A. Mokhtar and N. Noordin, "An exploratory study of industry 4.0 in Malaysia: A case of higher education institution in Malaysia," Indonesian Journal of Electrical Engineering and Computer Science, vol. 16, no. 2, pp. 978-987, Nov. 2019.

[15] Y. Chen, A. Gupta and L. Hoshower, "Factors that motivate business faculty to conduct research: An expectancy theory analysis," Journal of Education for Business, vol. 81, no. 4, pp. 179-189, Mar 2006. 
[16] M. F. Fox, "Publication, performance, and reward in science and scholarship," Higher education: Handbook of theory and research, vol. 1, pp. 255-282, 1985.

[17] T. H. Goodwin and R. D. Sauer, "Life cycle productivity in academic research: Evidence from cumulative publication histories of academic economists," Southern Economic Journal, pp. 728-743, Jan. 1995.

[18] Q. Hu and T. G. Gill, "IS faculty research productivity: Influential factors and implications," Information Resources Management Journal (IRMJ), vol. 13, no. 2, pp. 15-25, Apr. 2000.

[19] M. N. Lee, "Research assessment in institutions of higher learning," Khairur Rahim Ahmad Hilme, 2004.

[20] A. S. Levitan and R. Ray, "Personal and institutional characteristics affecting research productivity of academic accountants," Journal of Education for Business, vol. 67, no. 6, pp. 335-341, Aug. 1992.

[21] M. S. B. Ramli and A. B. Jusoh, "Expectancy theory analysis to conduct research at Malaysian Research University," International Journal of Economics and Financial Issues, vol. 5, no. 1S, pp. 366-372, Oct. 2015.

[22] R. E. Francis, "The Application of Binary Logistic Regression Analysis on Staff Performance Appraisal," Science Journal of Applied Mathematics and Statistics, vol. 5, no. 4, pp. 164-168, Jul 2017.

[23] W. F. W. Yaacob, S. A. M. Nasir, W. F. W. Yaacob and N. M. Sobri, "Supervised data mining approach for predicting student performance," Indonesian Journal of Electrical Engineering and Computer Science, vol. 16, no. 3, pp. 1584-1592, Dec. 2019.

[24] N. M. Samsudin, C. F. M. Foozy, N. Alias, P. Shamala, N. F. Othman and W. I. S. W. Din, "Youtube spam detection framework using naïve bayes and logistic regression," Indonesian Journal of Electrical Engineering and Computer Science, vol. 14, no. 3, pp. 1508-1517, Jun 2019.

[25] A. F. Cabrera, "Logistic regression analysis in higher education: An applied perspective," Higher education: Handbook of theory and research, vol. 10, pp. 225-256, Jan. 1994.

[26] R. L. Scheaffer, W. Mendenhall III, R. L. Ott and K. G. Gerow. Elementary survey sampling. Cengage Learning, 2011.

[27] N. J. Salkind. Omnibus Test, Encyclopedia of Research Design. SAGE Research Methods, 2010.

[28] N. A. M. Ghani, K. A. M. Ghani, Z. Mahmud, N. I. A. Hasan and N. M. Ramli, "Comparison between probit link and cloglog link functions for the identification of pathological staging in colorectal cancer data," International Journal of Mathematical Models and Methods in Applied Sciences, vol. 7, no. 1, pp. 14-21, 2013.

[29] H. Dundar and D. R. Lewis, "Determinants of research productivity in higher education," Research in higher education, vol. 39, no. 6, pp. 607-631, Dec. 1998.

[30] N. A. Basarudin, A. L. Yeon, N. Yaacob and R. A. Rahman, "Faculty Workload and Employment Benefits in Public Universities," International Review of Management and Marketing, vol. 6, no. 7S, pp. 73-82, Oct. 2016. 